\title{
Preparation of Sand Fly (Diptera: Psychodidae: Phlebotominae) Specimens for Histological Studies
}

\author{
Beatriz Gomes Brazil/ ${ }^{+}$, José Lino-Neto*, Reginaldo Peçanha Brazil \\ Centro de Pesquisas René Rachou-Fiocruz, Av. Augusto de Lima 1715, 300190-002 Belo Horizonte, MG, Brasil \\ *Departamento de Biologia Geral, UFV, Viçosa, MG, Brasil
}

\begin{abstract}
Phlebotominae sand fly specimens were prepared for histological and physiological studies. Different fixatives were tested on sectioned and whole bodied adult females in order to obtain good fixation and provide satisfactory penetration of the embedding media. All fixed specimens were infiltrated (up to seven days under $5^{\circ} \mathrm{C}$ ) and embedded in hydroxyethyl metacrylate. Two-three $\mu$ m sections were stained, mounted in Canada balsam and observed by light microscopy. Best results were achieved when whole bodied insects were double fixed in Bouin's and Carnoy's fluids $(4 \mathrm{~h} / 2 \mathrm{~h})$ and stained in Hematoxilin/Eosin or fixed in calcium formaldehyde and stained in mercury bromophenol blue.
\end{abstract}

Key words: Phlebotominae - histology - historesin preparations

There are few morphological studies on the internal organs of phlebotomine sand flies, vectors of the Leishmania spp. causing cutaneous and visceral leishmaniasis. Most published studies were done several years ago and involved predominantly Old World species (Adler \& Theodor 1926, Christophers et al. 1926, Perfilev 1928a,b, Lewis \& Minter 1960, Lewis 1965, Davis 1967). More recent publications on this subject refer to parasite-vector interactions or peritrophic membrane formation and blood digestion (Gemetchu 1974, Walters et al. 1987, 1989, 1995, Blackburn et al 1988).

Guzman et al. (1994) and Abassy et al. (1995 a, b, c) using histological methods studied the physiology of feeding and embryonic development on Phlebotomus duboscqi and $P$. papatasi respectively under the light microscope obtaining satisfactory results what indicate these methods as practical tools for physiological studies of sand flies.

The most recent literature on histological techniques suggests that historesin is a good alternative to paraffin for obtaining sections as thin as $0.5 \mu \mathrm{m}$, eliciting a better visualization of the tissue and cell structures (Junqueira 1995).

Based on this and aiming to study the functional morphology of the salivary glands of adult phlebotomine sand flies, we developed a procedure in which specimens of

This work received financial support from Capes, $\mathrm{CNPq}$ (Project 52307/95-6), Pronex and Fiocruz.

${ }^{+}$Corresponding author present address - Laboratório de Biologia Celular de Microrganismos, Departamento de Ultra-estrutura e Biologia Celular, Instituto Oswaldo Cruz-Fiocruz, Av. Brasil 4365, 21045-900 Rio de Janeiro, RJ, Brasil. Fax: +55-212260.4434. E-mail: bbrazil@ioc.fiocruz.br

Received 18 June 2002

Accepted 14 November 2002 different chronological and physiological ages could be obtained and prepared for histological studies.

Specimens of Lutzomyia longipalpis from a colony of the Laboratory of Leishmaniasis (CPqRR- Fiocruz) maintained in the laboratory according to the already preconized techniques (Brazil et al. 1997) were used. When pupation occurred the specimens were sexed as described by Brazil and Brazil (2000) and transferred individually to emergence vials. The vials were numbered and emergence of the insects monitored at hourly intervals. Unfed adult specimens were fixed at pre-determined times from the first hour after emergence until the fifth day. Five day-old sand flies were fed and fixed in the same way. Prior to fixation the insects were aspirated from the emergence containers, anaesthetized by cooling at $4{ }^{\circ} \mathrm{C}$ and placed on a glass slide in a drop of fixative under a stereoscopic microscope. After removing the appendages each specimen was transferred to glass vials containing the fixative of choice.

The following fixatives were evaluated for histology: Bouin's fluid, Carnoy's fluid, paraformaldeyde, Kleinberg's fluid and double fixation in Bouin's and Carnoy's fluids. Different fixation times were tested, ranging from 0.5-12 h. Specimens either had the scutellum removed, the thorax separated from the abdomen or where left entire.

At the end of fixation, the specimens were rinsed several times in distilled water for 45 min until no more yellowish color could be seen. They were than transferred to $70 \%$ alcohol. When necessary the insects were stored in alcohol at $4{ }^{\circ} \mathrm{C}$ to complete dehydration later.

For protein detection the insects were fixed by immersion in calcium formaldehyde for $24 \mathrm{~h}$, and then quickly rinsed in distilled water to remove excess. Following, the specimens were rinsed three more times for $15 \mathrm{~min}$ being posteriorly transferred to $70 \%$ alcohol.

In all cases dehydration was performed by passing the specimen three times for $10 \mathrm{~min}$ through each dilution of an alcoholic series $(70 \%, 90 \%$ and $95 \%$ ethanol). 
As embedding media we used historesin (hydroxyethyl metacrylate-Leica historesin embedding Kit-Leica instruments $\mathrm{GmbH}$ ). After several timing experiments, the following schedule was established to be used on the supplier's two-step recommended infiltration: (i) pre-infiltration in a 1:1 mixture of historesin infiltrating solution/ 95\% alcohol, kept overnight in the refrigerator; (ii) slow infiltration in the pure infiltrating resin at $5^{\circ} \mathrm{C}$ for at least a week. During the embedding the vessel containing the resin preparation was kept on ice inside a Styrofoam box to prevent early polymerization.

At the end of the embedding procedures the molds containing the specimens were kept at room temperature under cold light for about $2 \mathrm{~h}$ or until polymerization was completed. As this resin is somewhat hygroscopic and the $\mathrm{RH}$ in the laboratory was high, at the end of polymerization the molds containing the specimens were taken to an oven and kept at $60^{\circ} \mathrm{C}$ for one night. The specimens were then stored in a dessicator containing a dehumidifying agent (silica gel), until microtomy could be carried out.

Thin sections (2-3 $\mu \mathrm{m})$ of the specimens were obtained using a rotary microtome (Microm HM $340 \mathrm{E}$ ) with glass knives. The sections were recovered one by one in drops of distilled water on a clean microscopy slide and left on a hot plate for few hours to ensure adherence. Prior to utilization and at no more than a week the slides were cleaned for $1 \mathrm{~h}$ in a sulfochromic solution, rinsed in distilled water and left to dry at $70^{\circ} \mathrm{C}$ for one night (Chandler \& Schowenwolf 1987).

The sections were rehydrated and stained in Harris hematoxylin/eosin for general morphology studies. Mercury bromophenol blue was used for protein detection according to (Pearse 1972). After staining and drying, the slides were diaphanized in xylene and mounted in Canada balsam.

The methodology detailed above allowed preparations of various sand fly organs to be obtained. Good results were achieved for the observation of salivary glands, digestive tract, Malpighian tubules, ovaries, accessory glands, nerve cord, muscles and fat body and the results are presented in the Table and in the Figs 1 to11.

Studies of the functional morphology of the salivary glands as of other organs of adult insects require the exact age of the specimen to be known, since this could reveal age-related differences. Individual confinement of pupae and hourly monitoring of adult emergence ensured this in the present study. Phlebotomine sand flies are small insects and specimens can easily suffer mechanical damage, so that excessive manipulation should be avoided in morphological studies. Sexing the pupae and individualizing them in emergence vials, from which specimens can be obtained directly for fixation, can avoid such damage. Despite this fragility, the chitinous exoskeleton of the insects presents a barrier to the penetration of plastic infiltrating solutions and embedding media. This results in the loss of suitable material during microtomy, due to separation of the specimen from the resin block. To avoid this problem, various methods of fixation were tried. In spite of their good fixative properties, paraformaldehyde, Kleinberg's and Bouin's fixatives did not permit good infiltration of the resin. Carnoy's fluid reacted with chitin softening the insect body in such a way that it could be damaged during the subsequent procedures. It also leached material from the epidermis and consequently provided very poor histological preparations. Better results were achieved through the double fixation of whole insects in Bouin's and Carnoy's fixatives. These specimens were immersed individually in the former for $4 \mathrm{~h}$ and than transferred to the latter for $2 \mathrm{~h}$. Fixation in calcium formaldehyde was satisfactory and did not cause any problems with infiltration. However, the most satisfactory infiltration was achieved for insects fixed either in Bouin/ Carnoy's or calcium formaldehyde fixatives if the specimens were left infiltrating for at least a week in the refrigerator. Loss of material was also reduced.

Historesin is the best embedding medium for the histological preparation of sand fly-sized insects $(2-3 \mathrm{~mm})$ as infiltration may be carried on inside small glass or plastic vials using little quantities of resin. This process also

TABLE

Results obtained on different procedures of preparation of sand flies for histological studies of historesin (hydroxiethyl metacrylate) embedded specimens

\begin{tabular}{|c|c|c|c|}
\hline Fixative/procedure & Fixation $^{a}$ & Infiltration ${ }^{b}$ & Microtomy \\
\hline Bouin & Good from $4 \mathrm{~h}$ & Poor & Loss of specimens \\
\hline Kleinberg & Good from $4 \mathrm{~h}$ & Poor & Loss of specimens \\
\hline Paraformaldehyde & Good from $4 \mathrm{~h}$ & Poor & Loss of specimens \\
\hline Carnoy & $\begin{array}{l}\text { Loss of material at } \\
\text { any length of fixation }\end{array}$ & Good & Loss of specimens \\
\hline Bouin/Carnoy & Good fixation & Good & $\begin{array}{l}\text { Good sections, } \\
\text { little losses }\end{array}$ \\
\hline Halved insects & $\begin{array}{l}\text { Improved in all } \\
\text { fixatives }\end{array}$ & Improved & $\begin{array}{l}\text { Difficulties in } \\
\text { microtomy }\end{array}$ \\
\hline Whole bodied insects & $\begin{array}{l}\text { Good in Bouin/ } \\
\text { Carnoy }\end{array}$ & $\begin{array}{l}\text { Good improvement } \\
\text { if done at } 4^{\circ} \mathrm{C} \text { for } \\
\text { a week }\end{array}$ & $\begin{array}{l}\text { Very good sections, } \\
\text { great decrease in } \\
\text { losses }\end{array}$ \\
\hline
\end{tabular}

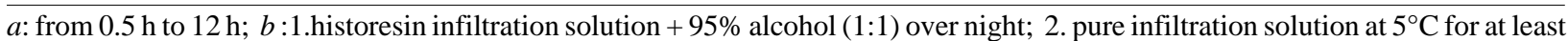
a week 


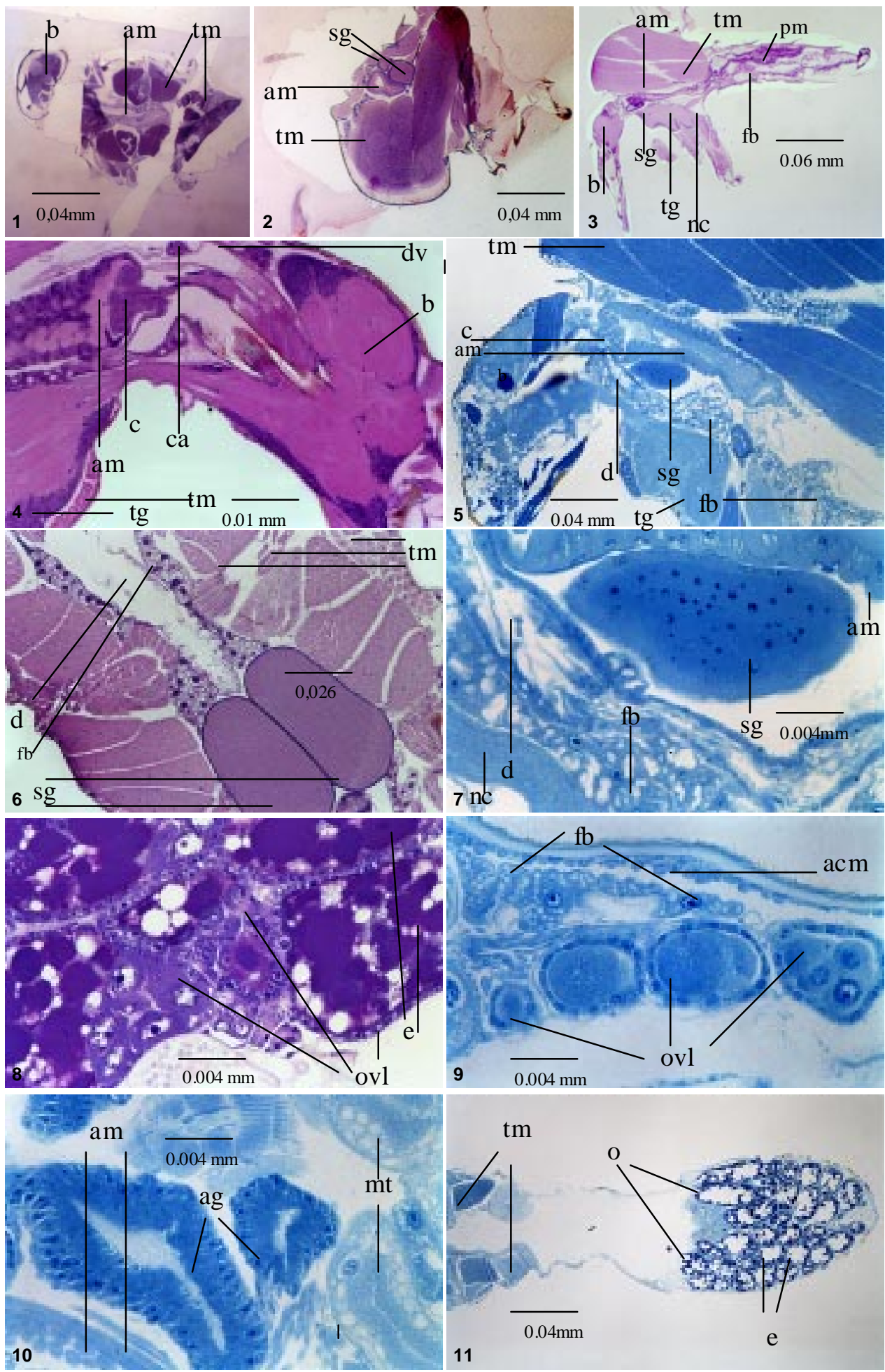

Sections of Lutzomyia longipalpis female specimens from different preparations embedded in historesin. Figs 1-2: respective ventral and sagittal sections, of thoracic specimens fixed in Carnoys fluid showing loss of material between the exoskeleton and muscles, poor resin infiltration and consequent damage due to microtomy. Col H/E 50X; 50X. Fig 3: median sagittal section of a whole Bouins/Carnoys-fixed insect, showing integrity of specimen within the resin section. Col H/E 15X. Figs 4, 6, 8: sections of Bouins/Carnoys-fixed specimens. Col H/E. Figs 5, 7, 9-11: sections of calcium formaldehyde-fixed specimens. Col-Mercury Bromophenol Blue. 4: sagittal section of head and part of thorax 100X; 5: sagittal section of thorax and head 50X; 6: ventral-longitudinal section of thorax 37.5X. 7: detail of figure 5 250X. Fig 8, 9, 11: sagittal $(8,9)$ and ventral $(11)$ sections of abdomen showing ovaries in different phases of maturation. 8: initial 250X; 11: eggs already formed 25X. Fig. 10: transversal section of the abdomen showing accessory glands of reproductive organs, Malpighian tubules and abdominal circular muscles. b: brain; c: cardia; d: diverticulum (crop); e: egg; o: ovaries; ovl: ovarioles; ag: accessory gland; am: anterior midgut; pm: posterior midgut; ams:abdominal muscles; acms:abdominal circular muscles; ca:corpora allata; dv: dorsal vessel; fb: fat body; mt: malpighian tubules; nc: nerve cord; sg: salivary gland; tg: thoracic ganglion; tm: thoracic muscles 
avoids excessive heat that would be harmful to the integrity of such small specimens. The possibility to obtain sections less than $5 \mu \mathrm{m}$ thick is interesting since it allows detailed examination of the tissues and cells under the light microscope, as well as permitting larger number of sections to be made from the same small specimen.

Microtomy is undoubtedly the more difficult step in this procedure due to the dimensions of the object to be sectioned and the thickness of the sections required. These are very difficult to see implying the use of high magnification lenses. Obtaining a ribbon of sections is too difficult and each section must be transferred to drops of water placed on slides using small surgical forceps. The common histological procedure of placing sections on a water bath and collecting them with a glass slide is difficult since they may not be seen on the surface of the water. Although somewhat time-consuming and laborious, this methodology is reliable and provided good preparations of different organs and tissues of sand flies and could be used for future studies of the internal morphology of these insects.

\section{ACKNOWLEDGEMENTS}

To Patricia Monteiro de Freitas Teixeira, Jeane Cristina Menezes Alves and Mariana Junqueira Pedras for their help in sand fly collections and maintenance of the insects in the laboratory; to José Eduardo Serrão, Federal University of Viçosa for critical reading of the manuscript, Bruce Alexander for revision of the English text and Heloiza Diniz, Laboratory of Image Treatment, Instituto Oswaldo Cruz for helping in preparation of the plate.

\section{REFERENCES}

Abbassy MG, Helmy N, Mostafa O, Stanton EL, Presley SM 1995a. Embryogenesis of the sandfly Phlebotomus papatasi (Diptera: Psychodidae): cell cleavage formation and gastrulation. Ann Entomol Soc Am 88: 809-814.

Abbassy MG, Helmy N, Mostafa O, Stanton EL, Presley SM 1995b. Embryogenesis of the sandfly Phlebotomus papatasi (Diptera: Psychodidae): organogenesis including segmentation, blastokinesis, mouthparts and alimentary canal. Ann Entomol Soc Am 88: 815-820.

Abbassy MG, Helmy N, Mostafa O, Stanton EL, Presley SM 1995c. Embryogenesis of the sandfly Phlebotomus papatasi (Diptera: Psychodidae): organogenesis of the nervous system, tracheal system, muscular system, and heart and gonad rudiments. Ann Entomol Soc Am 88: 821-826.

Adler S, Theodor O 1926. The mouthparts, alimentary tract, and salivary apparatus of the female in Phlebotomus papatasi. Ann Trop Med Parasit 20: 109-142
Blackburn K, Walbanks KR, Molineux DH, Lavin DR 1988. The peritrophic membrane of the sandfly Phlebotomus papatasi. Ann Trop Med Parasit 82: 613-619.

Brazil BG, Brazil RP 2000. Sexing sand fly pupae (Diptera: Psychodidae). Mem Inst Oswaldo Cruz 95: 471-472.

Brazil RP, Carneiro VL, Andrade Filho JD, Alves JCM, Falcão AL 1997. Biology of Lutzomyia lenti (Mangabeira) (Diptera:Psychodidae). An Soc Entomol Brasil 26: 191-193.

Chandler NB, Schoenwolf GC 1983. Wrinkle-free plastic sections for light microscopy. Stain Technol 58: 238-240.

Christophers SR, Shortt HE, Barraud PJ 1926. The development of the parasites of Indian Kala Azar in the sandfly Phlebotomus argentipes Annandale et Brunetti. Indian Med Res Mem 4: 123-125.

Davis NT 1967. Leishmaniasis in the Sudan Republic. 28. Anatomical studies on Phlebotomus orientalis Parrot and Parrot and Phlebotomus papatasi Scopoli (Diptera: Psychodidae). J Med Ent 4: 150-165.

Gemetchu T 1974. The morphology and fine structure of the midgut and peritrophic membrane of the adult female, Phlebotomus longipes Parrot and Martin (Diptera: Psychodidae) Ann Trop Med Parasitol 68: 111-124.

Guzman H, Walters LL, Tesh RB 1994. Histologic detection of multiple blood meals in Phlebotomus duboscqi (Diptera: Psychodidae). J Med Entomol 31: 890-897.

Junqueira LCU 1995. Histology revisited - Technical improvement promoted by the use of hydrophilic resin embedding. Ci Cult 47: 92-95.

Lewis DJ, 1965. Internal structural features of some Central American phlebotominae sandflies. Ann Trop Med Parasitol 59: 357-385.

Lewis DJ, Minter DM.1960. Internal structural changes in some African phlebotomine. Ann Trop Med Parasit 54: 351-365.

Pearse AGE 1972. Histochemistry Theoretical and Applied, Vol. II, 3rd ed., Churchill Livingstone, Edinburgh and London, $1518 \mathrm{pp}$.

Perfilev PP 1928 a. Sur l'anatomie des phlebotomes. Bull Soc Path Exot 21: 159-171.

Perfilev PP 1928 b. Sur l'anatomie des phlebotomes. Bull Soc Path Exot 21: 254-257.

Walters LL, Chaplin GL, Modi GB, Tesh RB 1989. Ultra structural biology of Leishmania chagasi in its vector, Lutzomyia longipalpis (Diptera: Psychodidae). Am J Trop Med Hyg 41: 295-317.

Walters LL, Irons KP, Guzman H, Tesh RB 1995. Peritrophic envelops of Lutzomyia spinicrassa (Diptera: Psychodidae). J Med Ent 32: 711-725.

Walters LL, Modi GV, Tesh RB, Burrage T 1987. Host parasite relationship of Leishmania mexicana mexicana and Lutzomyia abbonenci (Diptera: Psychodidae). Am J Trop Med Hyg 36: 294-314. 